\title{
ULTRASONIC INVESTIGATION OF BINARY LIQUID MIXTURES OF DMSO WITH PRIMARY ALCOHOLS
}

\author{
Sunita R. Dandwate \\ Department of Engineering Science, Sanjivani College of Engineering, Kopargaon \\ Dist. Ahmednagar M. S. (India) PIN 423603 \\ Email:drajendra2006@gmail.com / d_rajendra2006@rediffmail.com
}

\begin{abstract}
:
Binary liquid mixtures of Dimethyl sulfoxide with methanol, ethanol and propanol have been studied at $295.15 \mathrm{~K}$ and $300.15 \mathrm{~K}$. Acoustic, viscometric and volumetric data have been used to determine excess values of Gibb's free energy of activation, internal pressure and available volume. Deviation in data obtained for excess molar volume, viscosity and excess isentropic compressibility have been correlated with the help of Redlich Kister polynomial equation. Jouyban Acree model has been used to correlate experimental data and thus intermolecular interactions and non-ideal behavior have been interpreted for binary liquid mixtures.
\end{abstract}

Keywords: Redlich Kister polynomial equation, Jouyban Acree model, excess values, acoustic.

\section{INTRODUCTION:}

Acoustic study of binary liquid mixtures has become more demanded as it provides precise predictions of behaviour of molecules in the mixture. Study of behaviour of molecules or atoms in liquids and solids act as a tool to understand intermolecular interactions [1]. The data generated through precise knowledge of acoustic and thermodynamic study of binary liquid mixtures have been used in pharmaceutical, chemical as well as petrochemical industries for process designing purpose. Rigorous literature survey reveals the need of knowledge of excess thermodynamic parameters of liquid mixtures. Excess values of Gibb's free energy and internal pressure have been found sensitive for size, shape of molecules as well as their interactions [2-5]

In the present research work, attempt has been made to produce and analyze data through empirical, semi-empirical and theoretical equations by keeping in view the growing demand for precision in predicting the study of liquids and liquid mixtures. Excess values of isentropic compressibility, molar volume and deviation in viscosity have been correlated by Redlich-Kister polynomial equation. Data of binary coefficients and percentage deviation have been used to express composition and temperature dependence. A. Jouyban et al. have evaluated the model by calculating average percentage deviation (APD) using experimental and calculated viscosity and density data

\section{EXPERIMENTAL:}

All the chemicals used are of AR grade. 15 binary liquid mixtures have been prepared for each binary liquid mixture based on varied mole fractions and data have been generated for ultrasonic velocity, density and viscosity. Ultrasonic velocity has been measured by interferometry technique using ultrasonic interferometer (Mittal Enterprises, Model F81)[6-9] $25 \mathrm{ml}$, borosil glass specific gravity 
bottle has been used for the determination of density. Viscosity have been measured using Ostwald's viscometer. An electronic digital weighing balance (Shinko-make, 150gm × 0.001gm, Model DI-150, Pan Diameter 80 mm) has been used for weighing the samples. Constant temperature water bath has been used to acquire desired temperatures.

\section{Theory and calculations:}

Gibb's free energy have been calculated using relation [10]

$\eta V=N_{A} h \exp \left(\frac{\Delta G}{R T}\right)$

Where, $\mathrm{n}$ is viscosity, $\mathrm{V}$ is molar volume, NA is Avogadro's number, $\mathrm{h}$ is Planck's constant, $\Delta \mathrm{G}$ is Gibb's free energy of activation, $R$ is universal gas constant and $\mathrm{T}$ is absolute temperature.

\section{Internal pressure:}

Using following equation internal pressure have been calculated [11-12]

$$
\pi_{i n t}=b R T\left(\frac{k \eta}{U}\right)^{\frac{1}{2}} \frac{\rho^{2 / 3}}{M^{7 / 6}}
$$

Where, $\mathrm{k}=4.28 \times 10^{9}$ which is temperature independent constant.

$\mathrm{M}$ is molecular weight, $\mathrm{U}$ is ultrasonic velocity, $\eta$ is viscosity and $\rho$ is density and $T$ is temperature in Kelvin.

\section{Available volume:}

Available volume is given by

$$
V_{a}=V_{m}\left[1-\frac{U_{\text {exp }}}{U_{\infty}}\right]
$$

Excess parameters have been considered as a quantitative measure of non-ideal behavior of a liquid mixture. Excess value of any parameter is defined as the difference between experimental value and ideal value of that parameter

Redlich-Kister polynomial equation have been used to study the dependency of composition for excess molar volume $\left(V_{m}^{E}\right)$, excess isentropic compressibility $\left(K_{S}^{E}\right)$ and deviation in viscosity $(\Delta \eta)$, given by

$$
Y^{E}=X_{1}\left(1-X_{1}\right) \sum_{i=0}^{n} a_{i}\left[X_{1}-\left(1-X_{1}\right)\right]^{i}
$$

Where, $\mathrm{Y}^{\mathrm{E}}$ is the parameter $\left(V_{m}^{E}, \Delta \eta\right.$ or $\left.K_{S}^{E}\right), \quad \mathrm{X}_{1}$ and $\left(1-\mathrm{X}_{1}\right)$ are mole fractions of component 1 and 2 respectively. The coefficients $a_{i}$ have been obtained by fitting experimental data to polynomial equation [1315].

It has been observed that for all binary mixtures at both temperatures, datahave been found with best fits with four adjustable parameters. Experimental and calculated values have been correlated by means of standard deviation, $\sigma$.

$$
\sigma\left(Y^{E}\right)=\left[\frac{\sum\left(Y_{\text {exp }}-Y_{c a l}\right)^{2}}{n-m}\right]^{1 / 2}
$$

Where, ' $n$ ' is number of experimental data points, ' $\mathrm{m}$ ' is number of coefficients. $\mathrm{Y}_{\exp }$ and $\mathrm{Y}_{\mathrm{cal}}$ are experimental and calculated values of parameters respectively.

A. Jouyban et al., Ibrahim Sadek Khattab et al. [16-17] proposed and used a model to express applicability of relation of density of a liquid mixture with its composition and temperature quantitatively. According to this model, the density of binary liquid mixture at different temperatures is given by

$$
\ln \rho_{m, T}=f_{1} \ln \rho_{1, T}+f_{2} \ln \rho_{2, T}+f_{1} f_{2} \sum_{j=0}^{2} \frac{A_{j}\left(f_{1}-f_{2}\right)^{j}}{T}
$$


Where, $\rho_{m, T}, \rho_{1, T}$ and $\rho_{2, T}$ are densities of liquid mixture, component 1 and component 2 respectively at constant temperature. $f_{1}$ and $f_{2}$ are the volume fractions of component 1 and 2 respectively. $A_{j}$ is the Jouyban-Acree model constant. Also, data obtained for viscosity and density have been correlated by Jouyban Acree model.

\section{DISCUSSION AND RESULTS:}

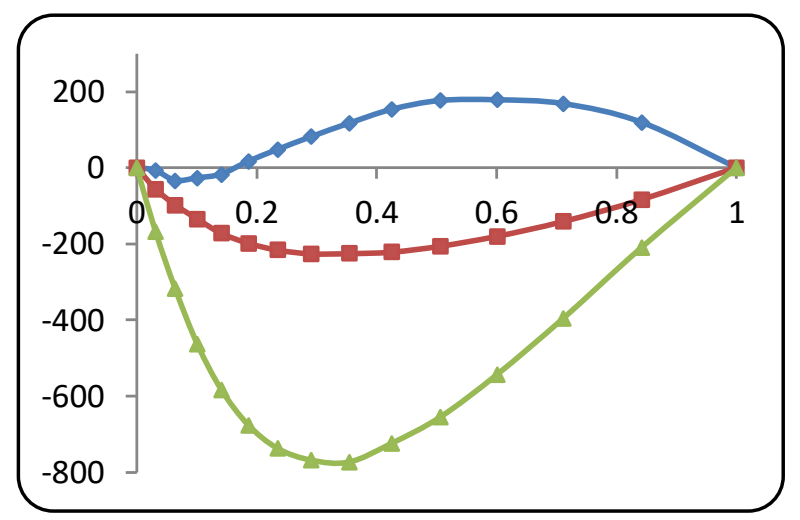

Plot of Excess Gibbs free energy against mole fraction $(\mathrm{X} 1)$ of DMSO with $(\bullet)$ Methanol, $(\square)$ Ethanol and $(\Delta)$ Propanolat 295.15 K

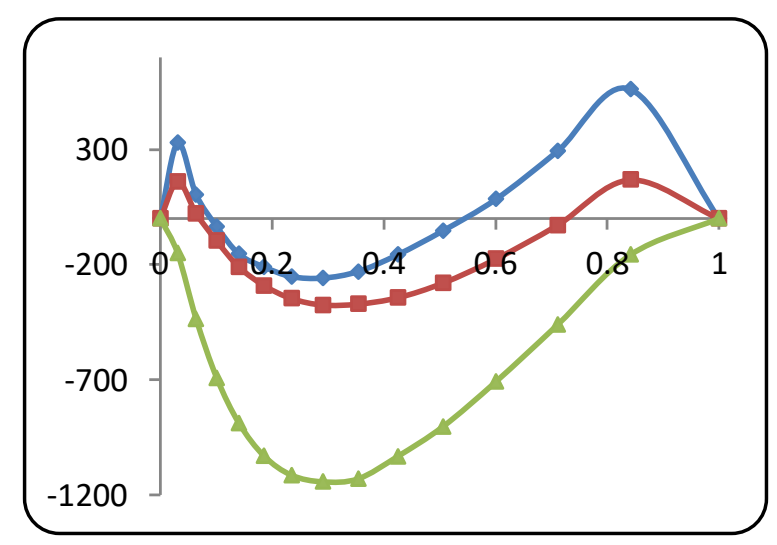

Plot of Excess Pi against mole fraction (X1) of DMSO with $(\bullet)$ Methanol, $(\square)$ Ethanol and $(\Delta)$ Propanol at $295.15 \mathrm{~K}$

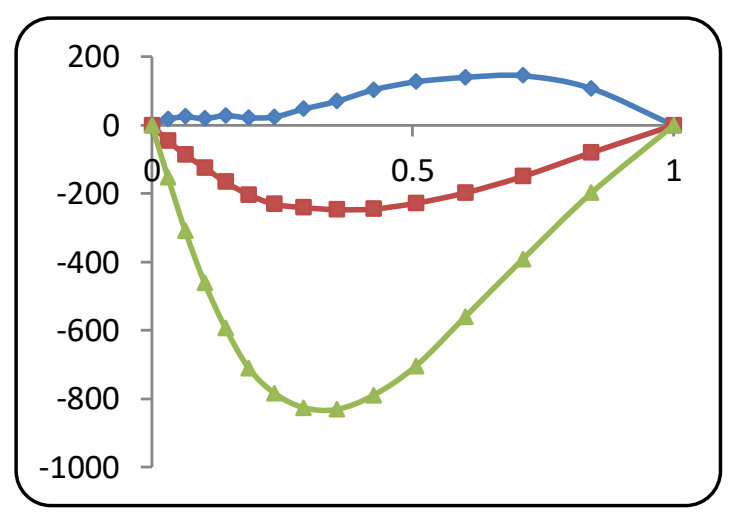

Plot of Excess Gibbs free energy against mole fraction (X1)
Plot of Excess Gibbs free energy against mole

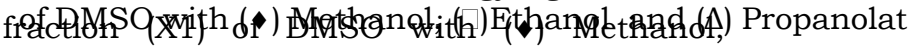
(3)

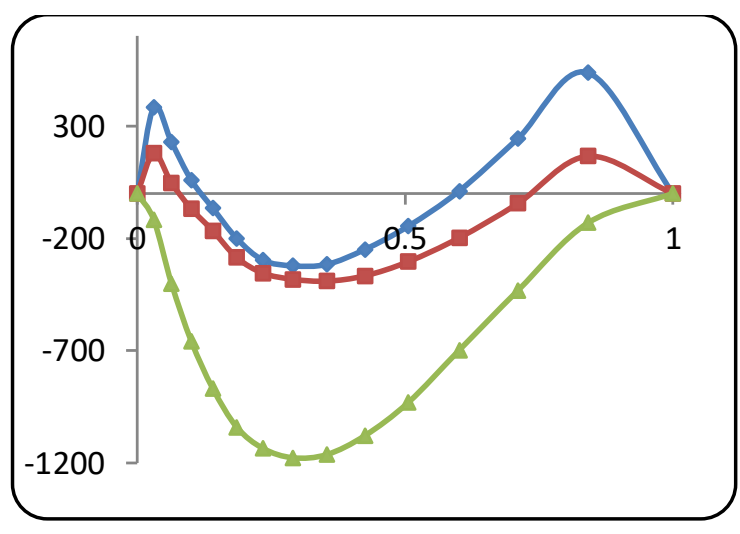

Plot of Excess Pi against mole fraction (X1) of DMSO with $(\bullet)$ Methanol, $(\square)$ Ethanol and $(\Delta)$ Propanol at $300.15 \mathrm{~K}$ 
In the present investigation, it has been observed that increase in temperature leads to more negative value of $\Delta \mathrm{G}^{\mathrm{E}}$. Its values are negative for binary liquid mixtures of ethanol and propanol.For DMSO + Methanol mixture, $\Delta \mathrm{G}^{\mathrm{E}}$ values are negative atlower mole fraction ofDMSO at $295.15 \mathrm{~K}$ temperature while at higher temperatures it is found with positive trend. Cohesive forces via hydrogen bonding, complex formation through charge transfer, dipole-dipole, dipole-induced dipole interactions, proper interstitial accommodation and orientational ordering tend to more compact structure causing positive contribution to $\pi_{i n t}^{E}$ and $\Delta G^{E}$

Plot so $\mathrm{f} \Delta G^{E}$ as a function of temperature are same as reported by A. Ali et al. [19]

It has been also reported that $\Delta G^{E}$ may be considered a trustworthy parameter to interpret the existence of intermolecular interactions in liquid mixtures. This further leads to suggest that between unlike molecules of binary liquid mixtures under investigation dispersion forces are operative.

Internal pressure has been calculated by using experimental values of ultrasonic velocity, density and viscosity. For binary liquid mixtures with methanol and ethanol their values are positive at lower molar concentration of DMSO, negative at about equimolar concentration and for large mole fraction of DMSO it again becomes positive. For propanol, all values show negative trend. As reported by R. K. Shukla et al. [20] negative sign of excess parameters is an indication of strong intermolecular interactions between hetero molecules of the mixture and hence it has been believed to form intermolecular complexes. As reported by K. Rajagopal and S. Chenthilnath, the attraction forces (i.e. cohesive forces) or dispersive forces between component molecules in a liquid mixture cannot be straightforwardly evaluated by any theory. However thermodynamic property like internal pressure helps in estimating them quiet accurately [1517].

The values of the coefficients of Redlich-Kister polynomial equation $\left(\mathrm{a}_{\mathrm{i}}\right)$ and standard deviations $(\sigma)$ for binary liquid mixtures of DMSO with methanol, ethanol and propanol at $\mathrm{T}=(295.15$ and $300.15 \mathrm{~K})$ have been represented in Table 1.

Data for standard deviation ( $\sigma$ )obtained for adjustable parameters in table predicts that their values are well acceptable and thus adjustable parameters have been best fitted at all temperatures for all binary mixtures.

In the present research, Jouyban Acree model has been used to correlate the experimentally obtained fundamental acoustic and thermodynamic parameters such as density and viscosity as well as ultrasonic velocity by calculating average percentage deviation (APD) between these and calculated values. Insight of non-ideal behavior of liquid mixtures has been discussed based on results and hence interpretations of intermolecular interactions have been carried out. The data obtained by applying Jouyban-Acree model for density, viscosity and ultrasonic velocity have represented in Table 2 in terms of model parameters $\left(\mathrm{a}_{\mathrm{i}}\right)$ and APD for binary liquid mixtures of DMSO with methanol, ethanol and propanol.

APD values listed in table reveals excellent applicability of Jouyban-Acree model to the experimental data of density and viscosity. Rigorous literature survey reveals that this model has not so far being used to correlate experimental data of ultrasonic velocity with calculated ones. However, an 
attempt has been made by us to use this model for ultrasonic velocity also and as observed form table, it has been concluded that for these data also the model is most suitable.

\section{CONCLUSION:}

$V_{a}^{E}$ are less negative for lower alcohols while more negative for higher ones and increase in temperature is found with its less negative values.

For liquid mixtures of DMSO with methanol and ethanol $\pi_{i n t}^{E}$ values are found to be positive towards pure stages of two components of liquid mixture and negative at middle concentration range. For remaining mixtures it show negative tendency.

With exceptional case of methanol, $\Delta \mathrm{G}^{\mathrm{E}}$ tends to be more negative with increase in temperature. Similar plots of $\Delta \eta$ and $\Delta G^{E}$ suggest that dispersion forces are operative.

Positive contribution to $\pi_{\text {int }}^{E}$ and $\Delta G^{E}$ and negative contribution to $V_{a}^{E}$ suggest that cohesive forces via hydrogen bonding, complex formation through charge transfer, dipoledipole, dipole-induced dipole interactions, proper interstitial accommodation and orientational ordering tend to more compact structure formation.

Data of standard deviation ( $\sigma$ )obtained for adjustable parameters using Redlich-Kister polynomial equation for excess molar volume, isentropic compressibility and deviation in viscosity speaks that these values are well satisfactory and thus adjustable parameters have been best fitted at all temperatures for all binary mixtures. Thus this justifies the dependency of composition.

Experimental data obtained for density, viscosity and ultrasonic velocity has excellent fit with Jouyban-Acree model.

\section{ACKNOWLEDGEMENT:}

Author is thankful to the management and Principal of SRES, Sanjivani College of Engineering, Kopargaon for extending research facilities and motivation to complete research work.

\section{REFERENCES:}

P.S. Nikam, Smt. M. C. Jadhav and Mehdi Hasan, Volumetric, viscometric and ultrasonic behavior of dimethyl Sulfoxide with normal alcohols (C1-C4) at $308.15 \mathrm{~K}, \mathrm{~J}$ Molecular liquids, Vol. 76 (1-2), 1998, 1-11.

A.K. Nain, Ultrasonic and viscometric study of molecular interactions in binary mixtures of aniline with 1-propanol, 2-propanol,2methyl-1-propanol, and2-methyl-2propanol at different temperatures, Fluid Phase Equilibria, 259, 2007, 218-227.

Nayeem, M. Kondaiah, K. Sreekanth, and D. Krishna Rao, Thermoacoustic, Volumetric, and Viscometric Investigations in Binary Liquid System of Cyclohexanone with Benzyl Benzoate at $\mathrm{T}=308.15,313.15$, and 318.15K, J Thermodynamics, 2014, 1-13.

P. S. Nikam, Smt. M. C. Jadhav and Mehdi Hasan, Volumetric, viscometric and ultrasonic behavior of dimethyl sulfoxide with normal alcohols (C1-C4) at $308.15 \mathrm{~K}$, Journal of Molecular Liquids, Vol. 76, 1998, 1-11.

D. V. Jahagirdar, B. R. Arbad, S. R. Mirgane, M. K. Lande and A. G. Shankarwar, Density, ultrasonic velocity and viscosity measurements of four pharmacologically significant drugs in methanol at $25^{\circ} \mathrm{C}$, Journal of Molecular Liquids, Vol. 75, 1998, 33-43.

Ernesto Vercher, A. Vicent Orchilles, Pablo J. Miguel, and Antoni Martinez_ Andreu, Volumetric and Ultrasonic studies of 1Ethyl-3-methylimidazolium Trifluromethane 
sulfonate Ionic Liquid with Methanol, Ethanol, 1-Propanol, and Water at Several temperatures, J. Chem. Eng. Data, Vol. 52, 2007,1468-1482.

S. Azhagiri, S. Jayakumar, R. Padmanaban, S. Gunasekran and S. Srinivasan, J Soln. Chemistry, Vol. 38 (12), 2009, 1648.

Suryanarayana C V and Kuppusamy J., J Acoustic Soc. Ind. 4, 1976, 75.

S. Elangovana and S. Mullainathanb, Intermolecular Interactions in Methyl Formate-Ethanol Mixtures at 303-313 K according to Ultrasonic Data, Russian $\mathrm{J}$ Physical Chemistry A, Vol. 88 (4), 2014, 601-606.

Gyan Prakash Dubey, Monika Sharma and Neelima Dubey, Study of densities, viscosities and speeds of sound of binary liquid mixtures of butan-1-ol with n-alkanes (C6, C8 and C10) at $\mathrm{T}=(298.15,303.15$, and 308.15) K, J Chem. Thermodynamics, Vol. 40 (2), 309-320.

Pandharinath S. Nikam and Sanjeevan J. Kharat, Density and Viscosity Studies of Binary Mixtures of N, N-Dimethylformamide with Toluene and Methyl Benzoate at (298.15, 303.15, 308.15, and 313.15) K, J. Chem. Eng. Data 50, 2005, 455-459.

M. V. Rathnam, Reema T. Sayed, Kavita R. Bhanushali and M. S. S. Kumar, Molecular interaction study of binary mixtures of methyl benzoate: Viscometric and ultrasonic study, J Molecular Liquids, 166, 2012, 9-16.

A. Jouyban, F. Fathi-Azarbyjani, M. Khoubnasabjafari and W. E. Acree, Mathematical Representation of the Density of Liquid Mixtures at Various Temperatures using Jouyban-Acree Model, Indian $\mathrm{J}$ Chem., Vol. 44A (8), 2005, 1553-1560.

Abolghasem Jouyban, Maryam Khoubnasabjafari, Zahra Vaez- Haramaleki, Zohreh Fekari, and William Eugene Acree
Jr., Calculation of the Viscosity of Binary Liquids at Various Temperatures Using Jouyban-Acree Model, Chem. Pharm. Bull. Vol. 53(5), 2005, 519-523.

K. Rajagopal and S. Chenthilnath, Excess Thermodynamic Studies of binary liquid mixtures of 2-methyl-2-propanol with ketones, Indian J Pure and Applied Physics, Vol. 48(5), 2010, 326-333.

G. V. Rama Rao, A. Vishvnatha Sarma, J. Siva Rama Krishna, C Rambabu, Evaluation of excess free volumes and excess internal pressures of binary solutions of Ochlorophenol at different temperatures, Indian $\mathrm{J}$ Pure and Applied Physics, Vol. 43(8), 2005, 602-608.

Sudhakar S. Dhondge and L. Ramesh, Isothermal compressibility and internal pressure studies of some non-electrolytes in aqueous solutions at low temperatures, J. Chem. Thermodynamics, Vol. 39(4), 2007, 667-673.

S. Elangovana, and S. Mullainathan, Intermolecular Interactions in Methyl Formate-Ethanol Mixtures at 303-313 K according to Ultrasonic Data, Russian Journal of Physical Chemistry A, Vol. 88 (4), 2014, 601-606.

A. Ali, K. Tiwari, A. K. Nain, Study of intermolecular interaction in Dimethylsulphoxide + 1-Alkanols (1Butanol, 1-Hexanol, 1-Octanol) at 303.15K, Phys. Chem. Liq., Vol. 38, 2000,459-473.

R. K. Shulka, S. K. Shukla, V.K. Pandey and Piyush Awashti, Excess internal pressure, excess energy of vaporization and excess pseudo-Gruneisen parameter of binary, ternary and quaternary liquid mixtures, J Molecular Liquids, 137, 2008, 104-109. 
Table: Binary coefficients of Redlich Kister polynomial equation and standard deviation

\begin{tabular}{|c|c|c|c|c|c|c|c|}
\hline DMSO + & $\mathbf{T}(\mathbf{K})$ & ao & $\mathbf{a}_{1}$ & $\mathbf{a}_{2}$ & $a_{3}$ & $\mathbf{a}_{4}$ & $\boldsymbol{\sigma}$ \\
\hline \multicolumn{8}{|c|}{$V^{E}$} \\
\hline Methanol & \multirow{3}{*}{295.15} & -1.9602 & 0.1814 & -0.5064 & 0.6028 & -0.0972 & 0.0030 \\
\hline Ethanol & & -1.8109 & -0.1822 & -0.5666 & 0.4883 & 0.7520 & 0.0022 \\
\hline Propanol & & -1.6997 & -0.4936 & -0.7745 & 0.1941 & 1.0201 & 0.0062 \\
\hline Methanol & \multirow{3}{*}{300.15} & -2.1881 & 0.3633 & 0.2707 & 0.1112 & -2.0054 & 0.0072 \\
\hline Ethanol & & -1.8971 & 0.0005 & -1.6022 & 0.6778 & 1.6385 & 0.0371 \\
\hline Propanol & & -1.8608 & -0.4793 & -0.5542 & 0.2470 & 0.2375 & 0.0067 \\
\hline \multicolumn{8}{|c|}{$\Delta \eta$} \\
\hline Methanol & \multirow{3}{*}{295.15} & -0.6540 & 0.1095 & -0.2372 & 0.2033 & 0.3515 & 0.0025 \\
\hline Ethanol & & -0.7279 & -0.0320 & -0.0403 & -0.0207 & -0.1173 & 0.0014 \\
\hline Propanol & & -2.1037 & 0.3289 & -0.1617 & 0.0205 & 0.1003 & 0.0022 \\
\hline Methanol & \multirow{3}{*}{300.15} & -0.6310 & 0.1433 & -0.0157 & -0.0556 & 0.2766 & 0.0014 \\
\hline Ethanol & & -0.6910 & -0.0632 & 0.0469 & 0.0022 & -0.0037 & 0.0019 \\
\hline Propanol & & -2.0105 & 0.3213 & 0.1575 & -0.0125 & 0.1847 & 0.0023 \\
\hline \multicolumn{8}{|c|}{$K_{S}^{E}$} \\
\hline Methanol & \multirow{3}{*}{295.15} & -665.6156 & 339.4432 & -171.5186 & 115.7575 & -81.3976 & 0.1142 \\
\hline Ethanol & & -498.3492 & 177.5971 & -56.0948 & -11.0207 & 53.2111 & 0.3281 \\
\hline Propanol & & -226.9041 & 50.8371 & -27.8220 & -13.5551 & 39.1210 & 0.24039 \\
\hline Methanol & \multirow{3}{*}{300.15} & -707.3733 & 362.1830 & -164.8916 & 131.0413 & -140.462 & 0.3344 \\
\hline Ethanol & & -531.0836 & 183.7069 & -68.5329 & 10.1378 & 41.1444 & 0.58285 \\
\hline Propanol & & -239.4364 & 53.2337 & -22.8944 & -5.4606 & 13.6900 & 0.12138 \\
\hline
\end{tabular}


Table: Jouyban-Acree model parameters and APD values

\begin{tabular}{|c|c|c|c|c|c|c|c|}
\hline Parameter & Liquid Mixture & ao & $\mathbf{a}_{1}$ & $\mathbf{a}_{2}$ & $\mathbf{a}_{3}$ & $\mathbf{a}_{4}$ & APD \\
\hline \multirow{3}{*}{ Density } & $\begin{array}{l}\text { DMSO + } \\
\text { Methanol }\end{array}$ & 73.3991 & $\begin{array}{c}- \\
16.7604\end{array}$ & 80.6404 & -0.1981 & 0.0169 & 0.4459 \\
\hline & $\begin{array}{l}\text { DMSO + } \\
\text { Ethanol }\end{array}$ & 29.4130 & 2.3228 & 66.1442 & -0.0422 & 0.0060 & 0.5895 \\
\hline & $\begin{array}{l}\text { DMSO + } \\
\text { Propanol }\end{array}$ & 1.8961 & 6.1396 & 59.2536 & 0.0015 & 0.0042 & 0.5694 \\
\hline \multirow{3}{*}{ Viscosity } & $\begin{array}{c}\text { DMSO + } \\
\text { Methanol }\end{array}$ & 18.9366 & 0.7848 & -0.0477 & 0.0940 & 0.2087 & 1.5791 \\
\hline & $\begin{array}{l}\text { DMSO + } \\
\text { Ethanol }\end{array}$ & $\begin{array}{c}- \\
118.9271\end{array}$ & 11.4191 & 0.0034 & 0.0589 & 0.0531 & 0.6640 \\
\hline & $\begin{array}{l}\text { DMSO + } \\
\text { Propanol }\end{array}$ & $\begin{array}{c}- \\
369.8728\end{array}$ & 16.5004 & -0.0343 & 0.0890 & 0.2192 & 2.0126 \\
\hline \multirow{3}{*}{$\begin{array}{c}\text { Ultrasonic } \\
\text { Velocity }\end{array}$} & $\begin{array}{c}\text { DMSO + } \\
\text { Methanol }\end{array}$ & 77.5212 & 46.7992 & -5.4654 & 44.1887 & 127.2101 & 1.2058 \\
\hline & $\begin{array}{l}\text { DMSO + } \\
\text { Ethanol }\end{array}$ & 53.8195 & -0.3289 & 2.1318 & -4.6893 & -3.4206 & 0.3028 \\
\hline & $\begin{array}{l}\text { DMSO + } \\
\text { Propanol }\end{array}$ & 11.8967 & 0.2560 & 3.2723 & -2.0028 & -2.3676 & 0.0552 \\
\hline
\end{tabular}

